\title{
Modeling and Control of Type-2 Wind Turbines for Sub-Synchronous Resonance Damping
}

\author{
Fernando Mancilla-David ${ }^{a}$, José Luis Domínguez-Garcíab ${ }^{\mathrm{b}}$, Mikel De \\ Prada $^{\mathrm{b}}$, Oriol Gomis-Bellmunt ${ }^{\mathrm{b}, \mathrm{c}}$, Mohit Singh ${ }^{\mathrm{d}}$, Eduard Muljadi $^{\mathrm{d}}$ \\ ${ }^{a}$ Department of Electrical Engineering, University of Colorado Denver, Denver, CO \\ 80217, USA \\ ${ }^{b}$ IREC Catalonia Institute for Energy Research, Jardins de les Dones de Negre 1, $2 a$. \\ 08930 Sant Adrià de Besòs, Barcelona (Spain) \\ ${ }^{c}$ Centre d'Innovació Tecnològica en Convertidors Estàtics i Accionaments \\ (CITCEA-UPC), Universitat Politècnica de Catalunya UPC, Av. Diagonal, 647, Pl. 2. \\ 08028 Barcelona, Spain \\ ${ }^{d}$ National Renewable Energy Laboratory (NREL), Golden, CO 80401, USA
}

Abstract

The rapid increase of wind power penetration into power systems around the world has led transmission system operators to enforce stringent grid codes requiring novel functionalities from renewable energy-based power generation. For this reason, there exists a need to asses whether wind turbines (WTs) will comply with such functionalities to ensure power system stability. This paper demonstrates that Type-2 WTs may induce sub-synchronous resonance (SSR) events when connected to a series-compensated transmission line, and with proper control, they may also suppress such events. The paper presents a complete dynamic model tailored to study, via eigenanalysis, SSR events in the presence of Type-2 WTs, and a systematic procedure to design a power system stabilizer using only local and measurable signals. Re-

Email address: fernando.mancilla-david@ucdenver.edu Corresponding author (Fernando Mancilla-David) 
sults are validated through a case study based on the IEEE first benchmark model for SSR studies, as well as with transient computer simulations. Keywords: IEEE first benchmark model, Local signals, Power system stabilizer, Rotor resistance control, Sub-synchronous resonance, Type-2 wind turbine, Wound rotor induction machine.

\section{Introduction}

Wind power is becoming an increasingly popular form of renewable energy around the world. The total wind power amount installed worldwide is currently more than $336 \mathrm{GW}$. According to a World Wind Energy Association report [1], Asia accounts for the largest share of wind power plants (WPPs) with 36.9\%, followed by Europe with 36.7\% and North America with 20.1\%. For many countries wind power has already become an important electricity source, e.g, Denmark with 34\% and Portugal, Spain and Ireland with penetration levels around 20\%. In the US, the total wind generation installed as of 2013 is more than 61 GW, representing $4.5 \%$ of the 2013 electricity demand [2]. Moreover, installation of offshore wind power is growing fast, since there is more constant wind and less space limitation. Due to the rapid increase of wind power penetration into the electricity production share and the pertinent reduction of power system inertia, transmission systems operators (TSOs) have developed restrictive grid codes for renewable energies. For example, WPPs must provide various ancillary services (frequency regulation [3], fault ride-through [4], among others [5]) as conventional synchronous generators do. Renewable energies with large grid integration such as photovoltaic and wind power, must thus be capable to provide ancillary 
services such as power oscillation damping [6,7], sub-synchronous resonance (SSR) mitigation[8] and synthetic inertia. Some of them are currently being provided by conventional generation or flexible ac transmission systems (FACTS) $[9,10,11]$. It is worth noting that the Spanish TSO and the European agency ENTSO-E have developed new drafts of the current grid codes where such concepts are already being referred $[12,13]$.

Some authors have already investigated the torsional dynamics of wind turbines (WTs) $[14,15]$, and the potential contribution of WPPs to damp power oscillations $[16,17]$. However, these studies mainly focus on variablespeed WTs (i.e., Type-3 and Type-4). Type- 3 and 4 WTs are equipped with a voltage source converter (VSC), and therefore their control scheme can easily be augmented to emulate FACTS control capabilities to damp power oscillations. Under the rubric of power system stabilizers (PSS) [18], a significant number of control schemes have been proposed for this purpose and some of them are already present in the field [19]. PSS functionalities based on artificial intelligence, $H_{\infty}$, or adaptive/predictive control have been utilized to augment the VSC's control scheme of Type- 3 and 4 WTs, all featuring acceptable performance $[19,20,21]$. On the other hand, Type2 WTs - based on a wound rotor induction generator (WRIG) - rely on a more modest power converter, namely, a rotor external resistor controlled by a simple dc chopper, and as a result have traditionally been perceived as less capable to provide ancillary services for power oscillations damping. Although the popularity of Type-2 WTs is decreasing within the wind power industry, they are still present on the market and on the grid [22]. Because of this, it is of interest to study whether they could induce SSR, as well as 
their capability to support power system stability.

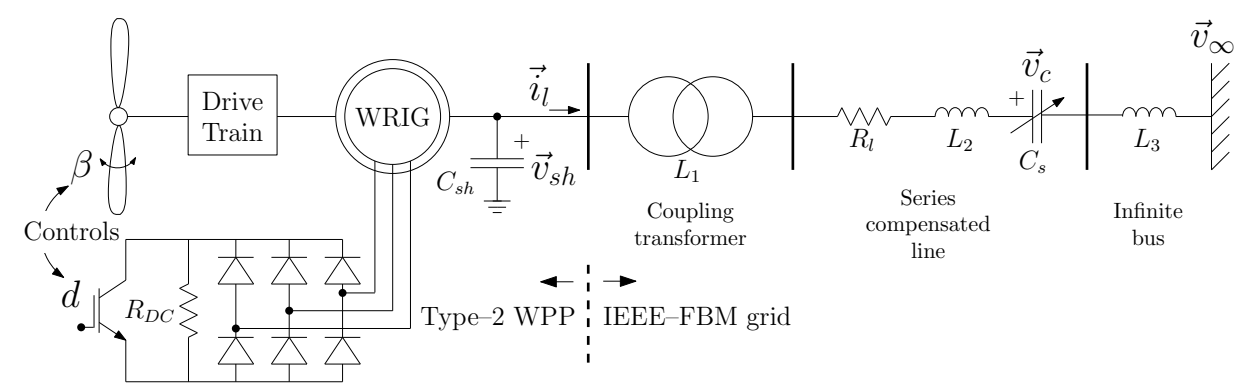

Figure 1: Schematic of the power system under study. The IEEE-FBM for SSR analysis has been modified replacing the synchronous generator by a Type-2 WPP [23].

Potential contribution of Type-2 WTs to mitigate torsional SSR events occurring as a result of the interaction of conventional synchronous generators and series-compensated transmission lines have already been analyzed by the authors of this paper in $[8,24]$. However, since a sub-synchronous oscillation was detected taking place among Type-3 WTs and a series-compensated line $[17,21]$, it is of interest to analyze whether Type-2 WTs may also engage in SSR events. This is the subject of this paper. The paper demonstrates that indeed Type-2 WTs can induce SSR events in series-compensated transmission lines under large levels of series compensation. The paper provides the theoretical foundations via eigenanalysis for the occurrence of SSR events, utilizing a modified version of the IEEE first benchmark model (IEEE-FBM) for SSR studies [23]. Furthermore, the paper provides a systematic design procedure to augment a Type -2 WT dc chopper control scheme with a PSS to effectively suppress SSR events. Fig. 1 show the power system to be studied, highlighting the modification to the IEEE-FBM.

The paper is organized as follows. Section 2 presents an overview of 
SSR events and their implications to the stability of a power system. Detailed modeling of the various system components is discussed in Section 3. Section 4 provides a systematic approach to tune a PSS tailored to SSR damping. The computer simulations of Section 5 validate the approach and the conclusions of Section 6 close the paper.

\section{Sub-synchronous resonance}

According to the IEEE SSR Working Group, a SSR event corresponds to an oscillation between the electric grid and the turbine-generator shaft at frequencies below the synchronous frequency of the grid [25]. These events were first detected at the Mohave power plant in Nevada, U.S.A., in the 1970's [23]. Since then, the SSR phenomenon have been extensively studied to understand, avoid and mitigate in case of occurrence by introducing additional controllers in synchronous power stations. In general, any system capable of exchanging energy at frequencies below the rated frequency is considered a potential source of SSR excitation. The most common case occurs in series-compensated transmission lines, where the interaction between the capacitor's capacitance and the transmission line's inductance introduces a natural frequency of resonance [26].

SSR events are usually classified into two different groups depending on the systems participating in the interaction. They are known as induction generator effect (IGE) and torsional interaction (TI) [18]. IGE can take place when the rotor resistance (which is seen negative because the rotor rotates faster than the magnetic field) is larger than the sum of armature and network resistances at a resonant frequency. This case leads to self- 
excitation increasing the voltages and currents delivered to the grid. On the other hand, TI related the interaction among electrical and mechanical parts. It occurs when the natural resonant frequencies of the mechanical parts (i.e., turbine and generator shaft) matches or is close to an electrical mode, leading to mechanical failure and shaft damage.

The resonant mode for a lossless series-compensated transmission line, $f_{n}$, can be computed using (1),

$$
f_{n}=f_{0} \sqrt{\frac{\sum X_{C}}{\sum X_{L}}},
$$

where $\sum X_{C}$ and $\sum X_{L}$ represents, respectively, the total capacitive and inductive reactance of the transmission line and $f_{0}$ is the nominal system frequency [18]. From (1), the super-synchronous and SSR frequencies $\left(f_{r}\right)$ can be determined by calculating the difference between the synchronous frequency of the system $\left(f_{0}\right)$ and previous resonance mode $\left(f_{n}\right)$ as

$$
f_{r}=f_{0} \pm f_{n}
$$

The value of $f_{r}$ provides an approximate idea about the frequencies of resonance that would appear in such power system conditions.

\section{System modeling}

The power system we consider for SSR analysis is based on a modified version the of the IEEE-FBM as shown in Fig. 1 [23]. The IEEE-FBM model introduced in [23] has been adapted by replacing the generating unit (a conventional synchronous generator) with a WPP based on Type-2 WTs. 
As illustrated in the figure, a Type-2 WT system corresponds to the aggregation of a wind turbine, a drive train, a WRIG, a power converter, and a shunt capacitor connected at the generator's output terminals. The WPP is modeled by aggregating a number $(N)$ of Type-2 WTs with a two-mass drive train mechanical system. The modeling of electrical components in the subsections below is performed in the $d-q$ reference frame utilizing dynamic phasors (i.e., $\vec{x}=x_{d}+j x_{q}$ ).

\subsection{Series-compensated transmission line model}

The IEEE-FBM grid can be readily lumped into a series RLC circuit as suggested in Fig. 2. The model is represented by (3) in the $d-q$ reference frame rotating synchronously at $\omega_{s}$ (which is defined as $\omega_{s}=\omega_{e l} / \omega_{b}$ being $\omega_{e l}$ and $\omega_{b}$ the electrical frequency and the base frequency values, respectively) $[27,28]$. Moreover, the parameters are defined in per unit.

$$
\begin{aligned}
L_{l} \frac{d i_{l d}}{d t} & =v_{s h d}-R_{l} i_{d}+\omega_{s} L_{l} i_{q}-v_{s d}-v_{\infty d} \\
L_{l} \frac{d i_{l q}}{d t} & =v_{s h q}-R_{l} i_{q}-\omega_{s} L_{l} i_{d}-v_{s q}-v_{\infty q} \\
C_{s} \frac{d v_{c d}}{d t} & =i_{l d}+\omega_{s} C_{s} v_{s q} \\
C_{s} \frac{d v_{c q}}{d t} & =i_{l q}-\omega_{s} C_{s} v_{s d} .
\end{aligned}
$$

In (3), $L_{l}$ aggregates the inductances of the coupling transformer $\left(L_{1}\right)$, transmission line $\left(L_{2}\right)$ and network $\left(L_{3}\right)$. That is, $L_{l}=L_{1}+L_{2}+L_{3}$.

\subsection{Type-2 WT model}

A Type-2 architecture encompasses a WT connected to a WRIG via a mechanical drive train. The WRIG features an external rotor resistance $\left(R_{D C}\right)$ 


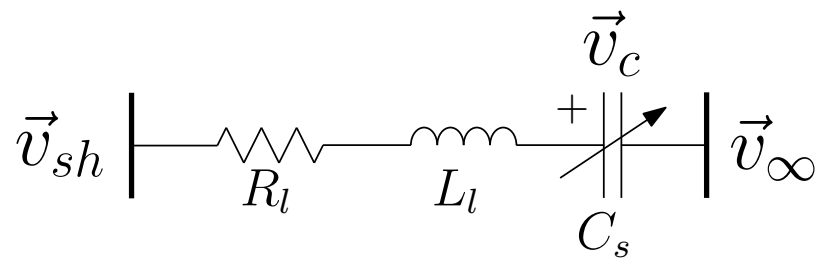

Figure 2: IEEE-FBM grid dynamic phasor-based circuit schematic.

connected to the rotor winding terminals by means of a power converter, including a three-phase diode bridge and a dc chopper. The dc chopper duty cycle $(d)$ provides the WT with some regulation capability; although, it is in a small range. A Type-2 WT usually regulates its maximum power generated during high wind conditions controlling the blades pitch angle $(\beta)$.

\subsubsection{Mechanical drive train}

The drive train of a WT transfers the aerodynamic torque on the blades into the generator shaft. It consists of the turbine, a low speed shaft, a gearbox, a high speed shaft, and the WRIG's rotor. Fig. 3 illustrates the drive train. A two-mass model of the mechanical system is used in this paper [29]. Such model can be represented by (4).

$$
\begin{aligned}
\frac{d \omega_{t}}{d t} & =\frac{1}{2 H_{t}}\left(T_{m}-k_{t r} \theta_{t w}-C_{t r} \omega_{e l}\left(\omega_{t}-\omega_{r}\right)\right), \\
\frac{d \theta_{t w}}{d t} & =\omega_{e l}\left(\omega_{t}-\omega_{r}\right), \\
\frac{d \omega_{r}}{d t} & =\frac{1}{2 H_{r}}\left(k_{t r} \theta_{t w}+C_{t r} \omega_{e l}\left(\omega_{t}-\omega_{r}\right)-T_{e}\right) .
\end{aligned}
$$

In (4), $\theta_{t w}, \omega_{t}$ and $\omega_{r}$ are the torsional twist, the turbine rotational speed and WRIG rotor rotational speed, respectively. Moreover, $H_{t}$ and $H_{r}$ represent the inertia constants, $C_{t r}$ is the damping coefficient between the turbine and WRIG rotor, and $k_{t r}$ denotes the shaft stiffness coefficient. The mechanical 


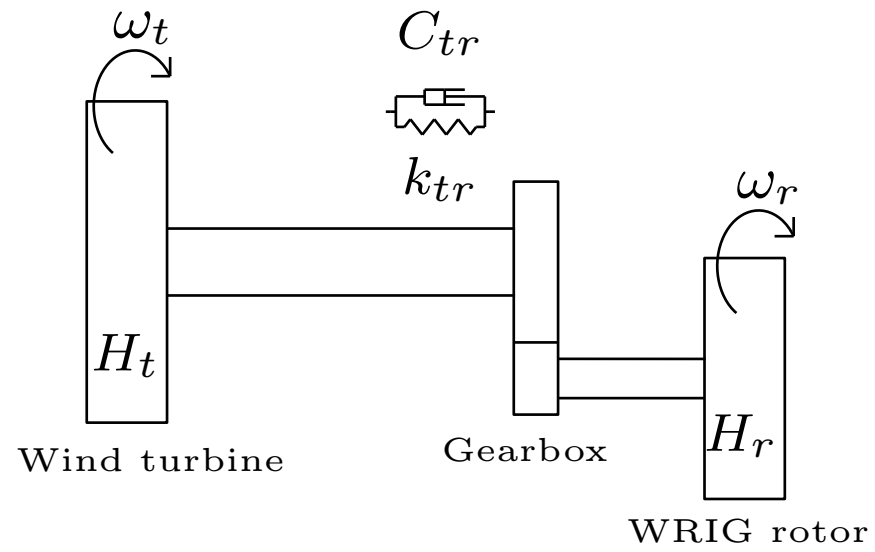

Figure 3: Schematic of the WT drive train represented by the two-mass model.

torque $T_{m}$ and the electromagnetic torque $T_{e}$ can be computed as,

$$
\begin{aligned}
T_{m} & =\frac{\rho R^{2} C_{p} v_{w}^{3}}{2 \omega_{t} T_{m b}} \\
T_{e} & =\frac{e_{s q}^{\prime}}{\omega_{s}} i_{s q}+\frac{e_{s d}^{\prime}}{\omega_{s}} i_{s d},
\end{aligned}
$$

where $\rho, R, C_{p}, v_{w}, \omega_{t}$ and $T_{m b}$ represent, respectively, the density of air, blades radius, power coefficient, wind speed, turbine rotational speed, and the base mechanical torque. The various parameters defining $T_{e}$ are explained in the next subsection.

\subsubsection{Wound rotor induction generator}

A schematic of the WRIG equivalent circuit is shown in Fig. 4. Although WRIGs are usually represented as suggested by the figure, in this paper the WRIG is modeled as an equivalent voltage source behind a transient impedance $[30,31]$. The state space model in the $d-q$ reference frame is 
given by (6).

$$
\begin{aligned}
\frac{d i_{s d}}{d t} & =\frac{\omega_{e l}}{L_{s}^{\prime}}\left(-R_{s}^{\prime} i_{s d}+\omega_{s} L_{s}^{\prime} i_{s q}+\frac{\omega_{r}}{\omega_{s}} e_{s d}^{\prime}-\frac{1}{T_{r} \omega_{s}} e_{s q}^{\prime}-v_{s h d}\right), \\
\frac{d i_{s q}}{d t} & =\frac{\omega_{e l}}{L_{s}^{\prime}}\left(-R_{s}^{\prime} i_{s q}+\omega_{s} L_{s}^{\prime} i_{s d}+\frac{\omega_{r}}{\omega_{s}} e_{s q}^{\prime}-\frac{1}{T_{r} \omega_{s}} e_{s d}^{\prime}-v_{s h q}\right), \\
\frac{d e_{s d}^{\prime}}{d t} & =\omega_{e l} \omega_{s}\left(-R_{2} i_{s q}-\frac{e_{s d}^{\prime}}{T_{r} \omega_{s}}+\left(1-\frac{\omega_{r}}{\omega_{s}}\right) e_{s q}^{\prime}\right), \\
\frac{d e_{s q}^{\prime}}{d t} & =\omega_{e l} \omega_{s}\left(R_{2} i_{s d}-\frac{e_{s q}^{\prime}}{T_{r} \omega_{s}}+\left(1-\frac{\omega_{r}}{\omega_{s}}\right) e_{s d}^{\prime}\right) .
\end{aligned}
$$

In (6), $i_{s d}$ and $i_{s q}$ are the $d-q$ components of the stator current. Similarly, $e_{s d}^{\prime}$ and $e_{s q}^{\prime}$ denote the $d-q$ components of the voltage source behind a transient impedance [31]. Moreover, $T_{r}$ represents the transient open-circuit time constant of the induction machine computed as $T_{r}=L_{r r} / R_{r}$ and $L_{s}^{\prime}$ is the transient (or short-circuit) reactance of the WRIG computed as $L_{s}^{\prime}=$ $L_{s s}-L_{m}^{2} / L_{r r}$. Resistors $R_{s}^{\prime}$ and $R_{2}$ are defined as $R_{s}^{\prime}=R_{s}+R_{2}$ and $R_{2}=$ $\left(L_{m} / L_{r r}\right)^{2} R_{r}^{\prime}$, respectively. $R_{r}^{\prime}$ includes both the rotor resistor $\left(R_{r}\right)$ and the external rotor resistor $\left(R_{e x t}\right)$, that is, $R_{r}^{\prime}=R_{r}+R_{\text {ext }}$. As shown in Fig. 1, the external rotor resistance is realized through a fixed resistor connected after a diode rectifier $\left(R_{D C}\right)$ and modulated through a dc chopper. The external resistor can be computed using (7).

$$
R_{e x t}=(1-d) \frac{\pi^{2}}{18} R_{D C}
$$

From (7) it is evident that the chopper's duty cycle provides the means for adjusting $R_{\text {ext }}$.

The WPP is modeled through averaging $N$ WTs based on wind turbine aggregation as detailed in Appendix A. This is widely accepted, since the dynamic response of a whole wind farm is faster than the slow dynamics of the power systems to be studied [15]. 


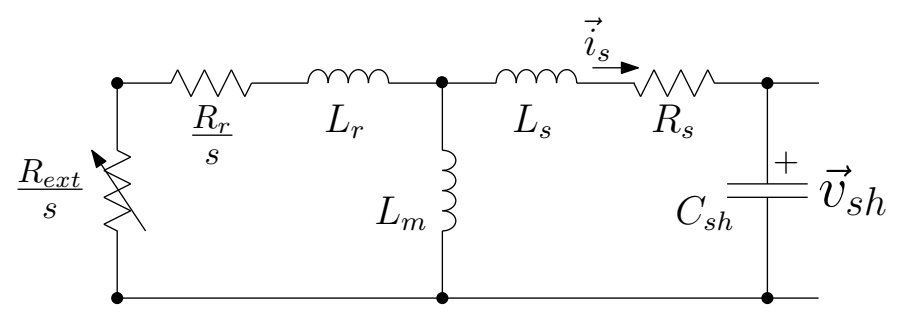

Figure 4: Dynamic phasor-based equivalent circuit schematic of a WRIG.

\subsection{Shunt capacitor bank}

WRIGs require reactive power to maintain their excitation. For this reason, a shunt capacitor bank is usually included at the WRIG terminals $[32,28]$. The state equations in the $d-q$ reference frame are,

$$
\begin{aligned}
& C_{s h} \frac{d v_{s h d}}{d t}=i_{s d}-i_{d}+\omega_{s} C_{s h} v_{s h q} \\
& C_{s h} \frac{d v_{s h q}}{d t}=i_{s q}-i_{q}-\omega_{s} C_{s h} v_{s h d} .
\end{aligned}
$$

\subsection{Overall system model}

The overall state space model describing the power system of Fig. 1 results from (3), (4), (6) and (8). The resulting system corresponds to a set of 13 nonlinear differential equations $\dot{x}=f(x, u)$ with

$$
x=\left[\begin{array}{lllllllllllll}
i_{l d} & i_{l q} & v_{c d} & v_{c q} & \omega_{t} & \theta_{t w} & \omega_{r} & i_{s d} & i_{s q} & e_{s d}^{\prime} & e_{s q}^{\prime} & v_{s h d} & v_{s h q}
\end{array}\right]
$$

and $u=\left[\begin{array}{llll}v_{\infty d} & v_{\infty q} & v_{w} & d\end{array}\right]$. As discussed below, $i_{s d}$ is selected as the state variable to be controlled for SSR damping, and therefore the output equation becomes $g(x, u)=i_{s d}$. The eigenvalues of the matrix $A=\partial f / \partial x$ provide the basis for the identification of resonant modes and the tuning of the PSS. The small signal model for the system is completed by defining the matrices $B=\partial f / \partial d, C=\partial g / \partial x$, and $D=\partial g / \partial d$. Appendix $B$ provides the 
mathematical background for the eigenanalysis-based approach we utilize in this paper.

\section{PSS systematic design}

In this section, an oscillation damping scheme is discussed. It is shown that standard PSS schemes developed for synchronous generators [18] may also be used in Type-2 WTs. The damping control scheme used in this paper is presented in Fig. 5 .

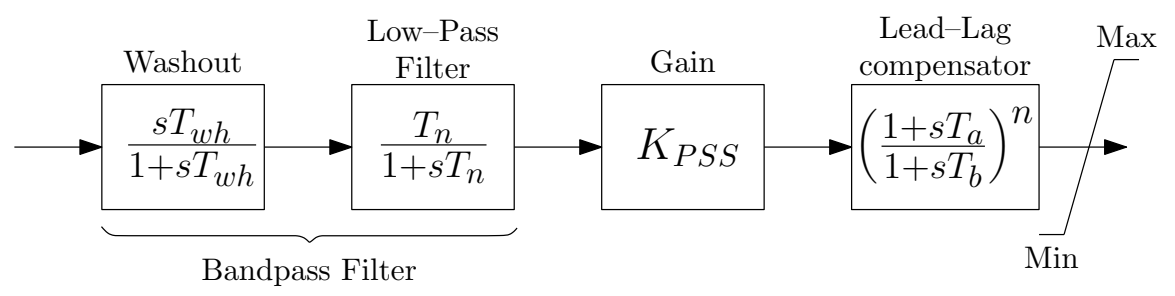

Figure 5: Block diagram of a classical PSS scheme.

The scheme includes a bandpass filter; a proportional gain; and a leadlag compensator. Systematic design considerations for these sub blocks are discussed below.

\subsection{Bandpass filter}

The bandpass filter is realized as the combination of a high- and a lowpass filter. The high-pass filter (also referred to as washout) removes the continuous component of the input signal and the low-pass filter limits the frequencies to be affected by the controller. The filter parameters must be fixed to enable the controller to respond within the desired frequency range. 
The time constants for the washout and and high-pass filter are selected as,

$$
\begin{aligned}
T_{w h} & =\frac{1}{2 \pi f_{c i}}, \\
T_{n} & =\frac{1}{2 \pi f_{c o}},
\end{aligned}
$$

where $f_{c i}$ and $f_{c o}$ are the desired cut-in and cut-out frequencies, respectively.

\subsection{Proportional gain}

The proportional gain $K_{P S S}$ provides the required magnitude modification to damp the oscillation. It is obtained by means of the root locus approach, which provides the system eigenvalue locations for different $K_{P S S}$ values, providing improved global damped response.

\subsection{Lead-lag compensator}

The lead-lag compensator provides the required phase compensation to the system. This compensator is used to modify the phase angle of the system around the frequency of interest. The design of the phase compensator is carried out by a procedure which requires the knowledge of both the frequency oscillation and the residue of the mode to be damped. The time constants $T_{a}$ and $T_{b}$ are computed as $T_{a}=c T_{b}$ and $T_{b}=1 /(\omega \sqrt{c})$. Moreover,

$\omega$ represents the frequency of the oscillation mode, $n$ the number of lead-lag functions required and $c$ a design variable which relates $T_{a}$ and $T_{b}$. These parameters are calculated using (10),

$$
\begin{aligned}
\theta_{\text {comp }} & =-\theta_{\text {residue }}, \\
n & =\operatorname{ceil}\left(\left|\frac{3 \theta_{\text {comp }}}{\pi}\right|\right), \\
c & =\frac{1+\sin \left(\frac{\theta_{\text {comp }}}{n}\right)}{1-\sin \left(\frac{\theta_{\text {comp }}}{n}\right)},
\end{aligned}
$$


where $\theta_{\text {residue }}$ is the phase angle of the residue of the eigenvalue.

\section{Illustrative case study}

In this section, the power system under study and its characteristics are shown and the control design method previously presented is applied.

\subsection{Power system}

As previously stated, an adaptation of the IEEE-FBM for SRR studies presented in Fig. 1 is considered in this paper. The WPP generates about $250 \mathrm{MW}$. It is modeled as the aggregation of $N=50 \mathrm{WTs}$ of $5 \mathrm{MW}$ of rated power each [33]. The WTs are assumed to be operating at their maximum power point $\left(C_{p}=0.4382\right)$ and at nominal wind $\left(v_{w}=12 \mathrm{~m} / \mathrm{sec}\right)$. The series compensation level in this study is $80 \%$. It is a high compensation level value, but it is important to remark that Type-2 WTs require reactive power compensation which is usually done by a shunt capacitors bank. This element also compensates the effect of series-compensation [28, 29]. The rest of the parameters considered for the system evaluation are given in Appendix A.

Evaluating (1) for the series compensated line of Fig. 2 allows to compute the resonant mode of the ideal system, yielding $f_{n}=53.67 \mathrm{~Hz}$. Thus, the super-synchronous and SSR frequencies of the lossless series-compensated line are 113.67 and $6.33 \mathrm{~Hz}$, respectively. The eigenvalues of the power system are presented in Table 1. It can be seen that the system has a supersynchronous and a SSR frequency at $117.88 \mathrm{~Hz}$ and $3.3 \mathrm{~Hz}$, respectively. These values are similar to those calculated above for an ideal system. More- 
over, the mode corresponding to the SSR features a positive real part and hence is unstable.

Table 1: Eigenvalues for $80 \%$ of series compensation without control.

\begin{tabular}{llll}
\hline Eigenvalue & Freq. $(\mathbf{H z})$ & Dominant state & Mode \\
\hline \hline$-19 \pm 2456.5 j$ & 390.96 & $v_{s h q}, v_{s h d}, i_{s q}, i_{s d}$ & Network \\
\hline$-24.5 \pm 2372.6 j$ & 377.62 & $i_{s d}, i_{s q}, v_{s h d}, v_{s h q}$ & Network \\
\hline$-7.2 \pm 740.7 j$ & 117.88 & $v_{c q}, v_{c d}, i_{l q}, i_{l d}$ & SuperSR \\
\hline$-5.8 \pm 195.3 j$ & 31.08 & $v_{c d}, v_{c q}, i_{l q}, i_{l d}$ & Electrical \\
\hline $\mathbf{0 . 1} \pm \mathbf{2 0 . 7 j}$ & $\mathbf{3 . 3 0}$ & $\omega_{r}, e_{s d}^{\prime}$ & SSR \\
\hline$-0.1 \pm 3 j$ & 0.47 & $\omega_{t}, \theta_{t w}$ & Torsional \\
\hline-5 & - & $e_{s q}^{\prime}$ & - \\
\hline
\end{tabular}

Fig. 6 presents the participation factors for the SSR mode. It can be observed it is mainly affected by electrical and mechanical state variables, namely $e_{s d}^{\prime}$ and $\omega_{r}$. This implies that such SSR mode is a TI-type SSR.

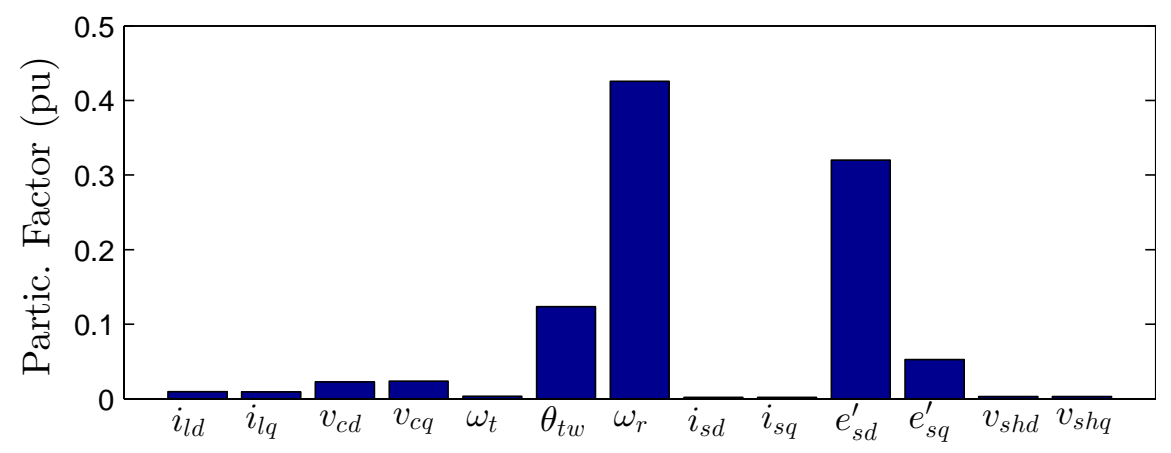

Figure 6: Participation factors for the SSR mode. 


\subsection{PSS design}

In this paper, the damping control is designed considering only local measurements avoiding the use of wide area measurement systems. These elements add some delay in the control scheme, making the system strongly dependent on communications [34]. For that reason, the PSS input signal of the control is selected as the $d$-component of the stator current $\left(i_{s d}\right)$. Moreover, this signal provides good observability of the power oscillation, since the $d$-components of the current carries the active power. The PSS output signal of the control is the de chopper duty cycle $(d)$ which modifies the external rotor resistance $\left(R_{\text {ext }}\right)$ value according to $(7)$.

The cut-in and cut-out frequencies are selected around 1 and $60 \mathrm{~Hz}$, respectively: $f_{c i}=0.08 \mathrm{~Hz}$ and $f_{c o}=63.66 \mathrm{~Hz}$. The washout and highpass filter time constants are computed using (9), yielding $T_{w h}=2$ and $T_{n}=0.0025$.

A root locus plot for the selection of $K_{P S S}$ is presented in Fig. 7, showing the eigenvalues location for $0 \leq K_{P S S} \leq-10$. $K_{P S S}$ is selected at -6.63 , since it provides a damping ratio for SSR over $5 \%$ and it does not affect critically any other oscillation mode.

As described in Subsection 4.3, the residue of the SSR mode is required to obtain the lead-lag compensator parameters. This residue for the SSR mode is $-180.97+90.449 j$ which is a complex value as expected. Using (10), the parameters are computed as $n=1, T_{a}=0.0781$ and $T_{b}=0.0299$. Fig. 8 summarizes the PSS implementation.

The frequency response of the loop gain with and without PSS control are illustrated in Fig. 9. It can be seen how the controller smooths the peak 


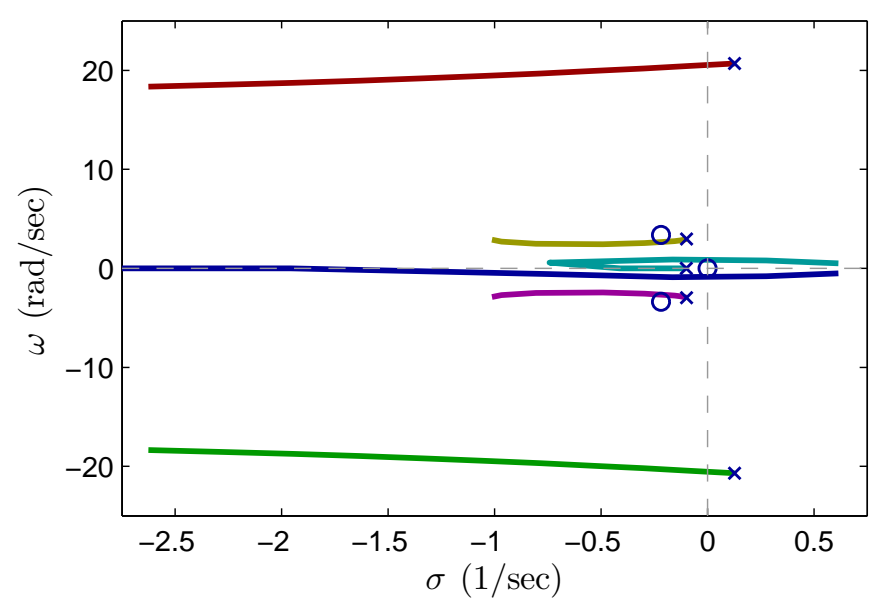

Figure 7: Root locus representation of the eigenvalues varying $K_{P S S}$ from 0 to -10 (SSR is the upper and lower lines).

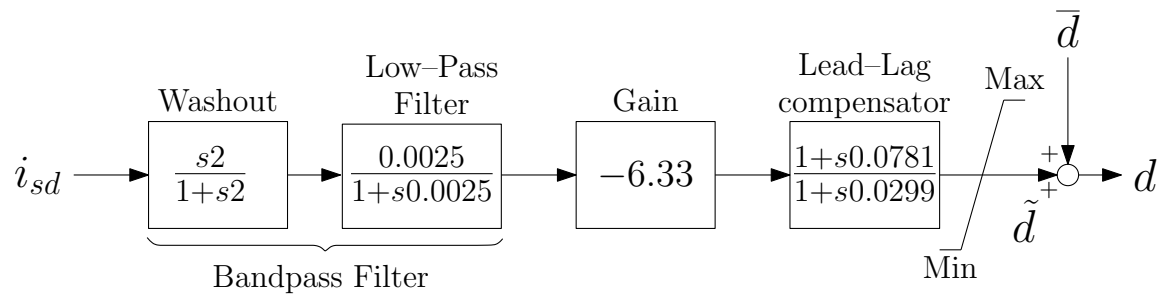

Figure 8: Block diagram for the PSS implementation. The average duty cycle $(\bar{d})$ comes from a conventional power control scheme.

of the SSR mode. Furthermore, Table 2 shows the eigenvalues of the system with the PSS controller included. It can be seen that after including the control, the SSR mode is moved to the left-hand side.

\subsection{Transient simulations}

In order to illustrate and validate the previous results, transient simulations are conducted in the Matlab-Simulink mathematical analysis software package. The time-domain response of the $d$-component of the stator cur- 


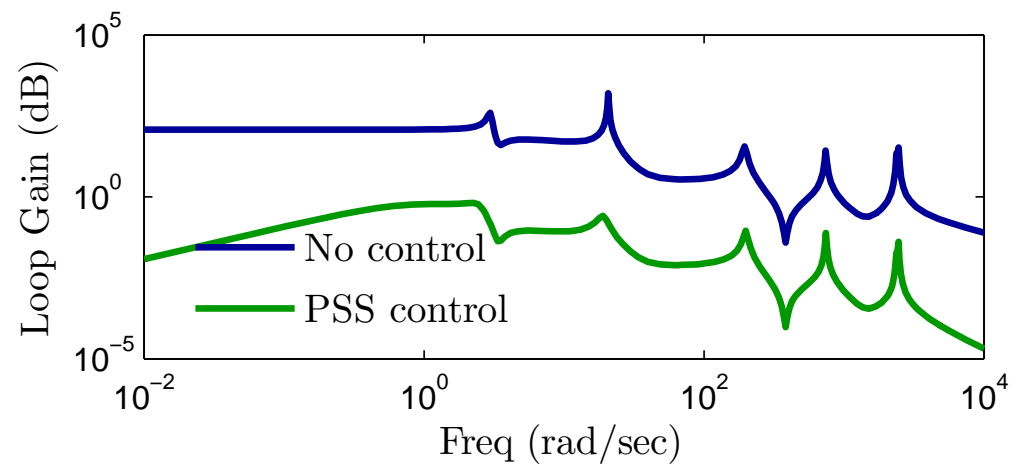

Figure 9: Bode plot for the loop gain without and with PSS control.

Table 2: Eigenvalues for $80 \%$ of series compensation with PSS control.

\begin{tabular}{llll}
\hline Eigenvalue & Freq. $(\mathbf{H z})$ & Dominant state & Mode \\
\hline \hline$-14.5 \pm 2457.5 j$ & 391.12 & $v_{s h q}, v_{s h d}, i_{s q}, i_{s d}$ & Network \\
\hline$-27.8 \pm 2369.8 j$ & 377.17 & $i_{s d}, i_{s q}, v_{s h d}, v_{s h q}$ & Network \\
\hline$-5.3 \pm 742.6 j$ & 118.18 & $v_{c q}, v_{c d}, i_{l q}, i_{l d}$ & SuperSR \\
\hline$-5.6 \pm 198.8 j$ & 31.64 & $v_{c d}, v_{c q}, i_{l q}, i_{l d}$ & Electrical \\
\hline$-\mathbf{1 . 5} \pm \mathbf{1 9 . 0} j$ & $\mathbf{3 . 0 3}$ & $\omega_{r}, e_{s d}^{\prime}$ & SSR \\
\hline$-0.4 \pm 2.5 j$ & 0.39 & $\omega_{t}, \theta_{t w}$ & Torsional \\
\hline-30.7 & - & $e_{s q}^{\prime}$ & - \\
\hline
\end{tabular}

rent, for both cases without and with PSS control, is shown in Fig. 10. The dynamic response of the system is triggered by a fast peak on the grid voltage which returns to its nominal value.

Fig. 10 suggests that the system under study without a PSS is unstable as predicted by the eigenvalue analysis conducted in Subsection 5.1. See Table 1. The figure also demonstrates that Type-2 based WPP may trigger a SSR event when they are installed nearby series-compensated transmission lines. 
When the dc-chopper control scheme is augmented with PSS functionalities it is illustrated that the Type-2 based WT is able to effectively damp the SSR event, consistent with the eigenvalues of Table 2 . This is an important result because Type -2 WTs have traditionally been perceived as generation with little capability to provide ancillary services. It could lead to new potential usages of current wind farms based on such wind turbine technology.

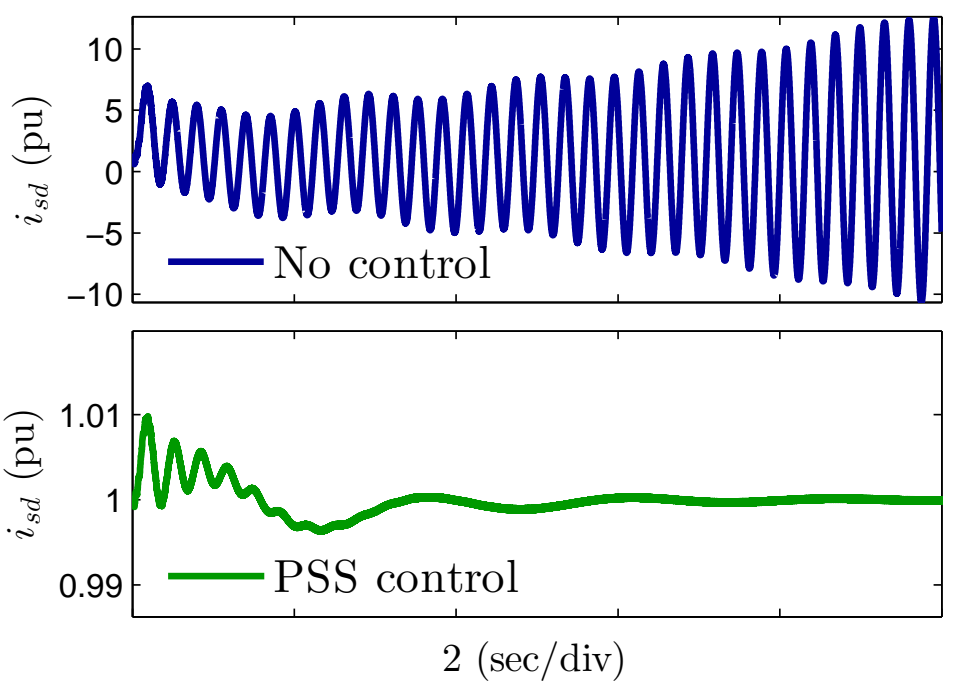

Figure 10: Illustration of the transient responses for $i_{d}$ without and with PSS control.

\section{Conclusion}

Motivated by the increasing penetration of wind power, it is being expected that in the near future wind power plants actively participate in power system dynamic events, complying with requirements similar to those offered by conventional synchronous generators. It has been well documented in the literature that WTs equipped with a voltage source converter (Type-3 and 
Type-4 WTs) are capable to damp power system oscillations, as the voltage source converter control can be augmented with a PSS scheme. This paper has illustrated that with a proper control of the external rotor resistance value, Type- 2 WTs are also capable to damp SSR oscillations in an effective manner. Furthermore, the proposed control scheme relies only on local and measurable signals, avoiding the use of wide area measurement systems. The paper has provided the mathematical basis for a Type-2 WT augmented control scheme capable of damping SSR events in power systems. A systematic approach based on eigenanalysis has been proposed for the PSS tuning process, and the theoretical analysis has been validated via transient simulations. The eigenanalysis-based modeling approach provided in the paper can also be utilized to identify SSR modes as well as other low-frequency oscillation modes. Furthermore, the model may also be utilized as a benchmark to assess the performance of more advanced PSS schemes - for example those based on artificial intelligence, $H_{\infty}$, or adaptive/predictive control.

\section{Ackowledgments}

This work was supported by the EU $7^{\text {th }}$ framework programs FP7-ENERGY2013 IRPWIND Project (under Grant Agreement 609795), by the Ministerio de Economía y Competitividad, Plan Nacional de I+D+i under Project ENE2012-33043 and also supported by the U.S. Department of Energy under Contract No. DE-AC36-08-GO28308 with the National Renewable Energy Laboratory. 


\section{Appendix A. Parameters for case study}

Tables A.3 and A.4 specify parameters for the IEEE-FBM grid and WPP utilized in this paper.

Table A.3: IEEE-FBM Grid Parameters (500 kV, 892.4 MVA, $60 \mathrm{~Hz}$ )

\begin{tabular}{llll}
\hline Impedance & Value $(\mathbf{p u})$ & Impedance & Value $(\mathbf{p u})$ \\
\hline \hline$R_{l}$ & 0.02 & $X_{1}$ & 0.14 \\
$X_{2}$ & 0.5 & $X_{3}$ & 0.06 \\
\hline
\end{tabular}

\section{Appendix B. Mathematical basis for eigenanalysis}

As discussed in Subsection 3.4, the power system of Fig. 1 is described by a set nonlinear differential equations. For modal analysis, we compute the matrices $A, B, C$ and $D$ in order to obtain a linear representation of the power system around an operating point. The linear dynamics is then given by $\Delta \dot{x}=A \Delta x+B \Delta d$ and $\Delta i_{s d}=C \Delta x+D \Delta d$, where $\Delta$ denotes a small variation of the variable around its operating point. The stability of the linear system is analyzed by means of the eigenvalues of the state matrix $A, \lambda_{i}=\sigma_{i} \pm j \omega_{i}$ with $i=1,2, \ldots 13$. The real part $\sigma_{i}$ of $i^{\text {th }}$ eigenvalue $\lambda_{i}$ represents the amplitude damping the mode, while the imaginary part $\omega_{i}$ corresponds to the frequency of the oscillation.

We then compute the right and left eigenvectors defined as $A \Phi_{i}=\lambda_{i} \Phi_{i}$ and $\Psi_{i} A=\lambda_{i} \Psi i$, respectively. These vectors are orthogonal, and in power system analysis they are usually normalized $\left(\Psi_{i} \Phi_{i}=I\right)$. The participation matrix is computed from the right and left eigenvectors $\left(P=\Phi_{i} \Psi_{i}^{T}\right)$. The 
Table A.4: WRIG \& Turbine Parameters for N=50 WTs

\begin{tabular}{lll}
\hline Parameter & Variable & Value \\
\hline \hline Rated power & $P_{\text {rated }}$ & $5 \mathrm{~N} \mathrm{MVA}$ \\
Rated voltage & $V_{\text {rated }}$ & $0.69 \mathrm{kV}$ \\
Electrical base frequency & $f$ & $60 \mathrm{~Hz}$ \\
Synchronous speed & $\omega_{s}$ & $1 \mathrm{pu}$ \\
Stator resistance & $R_{s}$ & $0.005 / \mathrm{N} \mathrm{pu}$ \\
Rotor resistance & $R_{r}$ & $1.1 R_{s}$ \\
External resistance & $R_{D C}$ & $0.04 / \mathrm{N} \mathrm{pu}$ \\
Mutual inductance & $L_{m}$ & $4 / \mathrm{N} \mathrm{pu}$ \\
Stator inductance & $L_{s s}$ & $1.01 L_{m}$ \\
Number of poles pair & $n_{p p}$ & 2 \\
Rotor inductance & $L_{r r}$ & $1.006 L_{s s}$ \\
Turbine inertia & $H_{t}$ & $4 \mathrm{~N} \mathrm{sec}$ \\
WRIG rotor inertia & $H_{r}$ & $0.1 H_{t}$ \\
Gearbox ratio & $n_{g b}$ & 145.5 \\
Base torque & $T_{m b}$ & $n_{g b} P_{\mathrm{rated}} /\left(\omega_{e l} / n_{p p}\right) \mathrm{Nm}$ \\
Damping coefficient & $C_{t r}$ & $1 \mathrm{E}-5 \mathrm{~N} \mathrm{pu} \cdot \mathrm{sec} / \mathrm{el} . \mathrm{rad}$ \\
Stiffness coefficient & $k_{t r}$ & $0.3 \mathrm{~N} \mathrm{pu} / \mathrm{el} \cdot \mathrm{rad}$ \\
Blades radius & $R$ & $58.6 \mathrm{~m}$ \\
\hline
\end{tabular}

values of the participation matrix are often complex; however, only the magnitude gives useful information. A participation factor provides a measure of the contribution of each state variable to a particular eigenvalue, and in particular, to its imaginary part. Therefore, we can associate state variables contributing to SSR as discussed in Subsections 5.1 and 5.2. 
Furthermore, a residue $R_{k}$ provides an idea of how the mode $\lambda_{k}$ is affected by the input $u_{i}=\Delta d$ and how visible it is from the output $y_{j}=\Delta i_{s d}$. The residues give the gain of the transfer function of the system $G(s)=\Delta i_{s d} / \Delta d$ (with $G(s)=C(s I-A)^{-1} B+D$ ) from input to output for the oscillation mode selected. They also provide the phase angle between input and output. They can be computed as $R_{k}=c_{j} \phi_{k} \psi_{k} b_{i}$, where $\phi_{k}$ and $\psi_{k}$ are the right and left eigenvectors of the state matrix $A$ associated to the eigenvalue $\lambda_{k}$, and $c_{j}$ and $b_{i}$ are the corresponding entries of the matrices $C$ and $B$, respectively. The residues can then be evaluated and subsequently utilized in the PSS' lead-lag compensator design process as discussed in Subsections 4.3 and 5.2. 


\section{References}

[1] The World Wind Energy Asociation, 2014 Half-Year Report, Tech. rep. (2014).

[2] U.S. Department of Energy, 2013 Wind Technologies Market Report, Tech. rep. (2013).

[3] S. Ghosh, N. Senroy, Electromechanical Dynamics of Controlled Variable-Speed Wind Turbines, IEEE Systems Journal PP (99) (2013) $1-8$.

[4] O. Gomis-Bellmunt, A. Junyent-Ferre, A. Sumper, J. Bergas-Jane, Ride-Through Control of a Doubly Fed Induction Generator Under Unbalanced Voltage Sags, IEEE Transactions on Energy Conversion 23 (4) (2008) 1036-1045.

[5] N. Ullah, K. Bhattacharya, T. Thiringer, Wind Farms as Reactive Power Ancillary Service Providers Technical and Economic Issues, IEEE Transactions on Energy Conversion 24 (3) (2009) 661-672.

[6] E. Muljadi, C. Butterfield, B. Parsons, A. Ellis, Characteristics of Variable Speed Wind Turbines Under Normal and Fault Conditions, in: IEEE Power Engineering Society General Meeting, 2007, pp. 1-7.

[7] R. Shah, N. Mithulananthan, R. Bansal, Oscillatory Stability Analysis With High Penetrations of Large-Scale Photovoltaic Generation, Energy Conversion and Management 65 (0) (2013) 420-429. 
[8] M. De Prada, F. Mancilla-David, J. Domínguez-García, E. Muljadi, M. Singh, O. Gomis-Bellmunt, A. Sumper, Contribution of Type-2 Wind Turbines to Sub-Synchronous Resonance Damping, International Journal of Electrical Power \& Energy Systems 55 (2014) 714-722.

[9] H. Shayeghi, A. Safari, H. Shayanfar, PSS and TCSC Damping Controller Coordinated Design Using PSO in Multi-Machine Power System, Energy Conversion and Management 51 (12) (2010) 2930-2937.

[10] M. Shakarami, A. Kazemi, Assessment of Effect of SSSC Stabilizer in Different Control Channels on Damping Inter-Area Oscillations, Energy Conversion and Management 52 (3) (2011) 1622-1629.

[11] J. Devotta, M. Rabbani, S. Elangovan, Application of Superconducting Magnetic Energy Storage Unit for Damping of Subsynchronous Oscillations in Power Systems, Energy Conversion and Management 40 (1) (1999) 23-37.

[12] M. de Industria Turismo y Comercio, Secretaria de Estado de Energía, Instalaciones Conectadas a la Red de Transporte y Equipo Generador: Requisitos Mínimos de Diseño, Equipamiento, Funcionamiento, Puesta en Servicio y Seguridad, Tech. rep., Red Eléctrica (Oct. 2008).

[13] ENTSO-E, ENTSO-E Network Code for Requirements for Grid Connection Applicable to all Generators (Mar. 2013).

[14] A. Burlibaşa, E. Ceangă, Frequency Domain Design of Gain Scheduling Control for Large Wind Systems in Full-Load Region, Energy Conversion and Management 86 (0) (2014) 204-215. 
[15] V. Akhmatov, H. Knudsen, An Aggregated Model of a Grid-Connected, Large-Scale, Offshore Wind Farm for Power Stability InvestigationsImportance of Windmill Mechanical System, Electrical Power \& Energy Systems 24 (9) (2002) 709-717.

[16] F. Hughes, O. Anaya-Lara, N. Jenkins, G. Strbac, Control of DFIGbased Wind Generation for Power Network Support, IEEE Transactions on Power Systems 20 (4) (2005) 1958-1966.

[17] L. Fan, Z. Miao, Mitigating SSR using DFIG-Based Wind Generation, IEEE Transactions on Sustainable Energy 3 (3) (2012) 349-358.

[18] P. Kundur, Power System Stability and Control, Mc Graw Hill, 1994.

[19] J. Domínguez-García, O. Gomis-Bellmunt, F. Bianchi, A. Sumper, Power Oscillation Damping Supported by Wind Power: A Review, Renewable and Sustainable Energy Reviews 16 (7) (2012) 4994-5006.

[20] K. Alawasa, Y.-R. Mohamed, W. Xu, Modeling, Analysis, and Suppression of the Impact of Full-Scale Wind-Power Converters on Subsynchronous Damping, IEEE Systems Journal 7 (4) (2013) 700-712.

[21] H. Ghasemi, G. Gharehpetian, S. A. Nabavi-Niaki, J. Aghaei, Overview of Subsynchronous Resonance Analysis and Control in Wind Turbines, Renewable and Sustainable Energy Reviews 27 (0) (2013) 234-243.

[22] P. Rosas, Dynamic Influences of Wind Power on the Power System, Ph.D. thesis, Technical University of Denmark (Mar. 2003). 
[23] IEEE Subsynchronous Resonance Task Force, First Benchmark Model for Computer Simulation of Subsynchronous Resonance, IEEE Transactions on Power Apparatus and Systems 96 (5) (1977) 1565-1572.

[24] M. De Prada-Gil, J. Domínguez-García, F. Mancilla-David, E. Muljadi, M. Singh, O. Gomis-Bellmunt, A. Sumper, Type-2 Wind Turbine with Additional Sub-Synchronous Resonance Damping, in: IEEE Green Technologies Conference, 2013, pp. 226-232.

[25] IEEE SSR Working Group, Terms, Definitions, and Symbols for Subsynchronous Oscillations, IEEE Transactions on Power Apparatus and Systems 104 (6) (1985) 1326-1334.

[26] IEEE Committee Report, Readers guide to subsynchronous resonance, IEEE Transactions on Power Systems 7 (1) (1992) 150-157.

[27] L. Fan, C. Zhu, Z. Miao, M. Hu, Modal Analysis of a DFIG-Based Wind Farm Interfaced with a Series Compensated Network, IEEE Transactions on Energy Conversion 26 (4) (2011) 1010-1020.

[28] R. Varma, A. Moharana, SSR in Double-Cage Induction GeneratorBased Wind Farm Connected to Series-Compensated Transmission Line, IEEE Transactions on Power Systems 28 (3) (2013) 2573-2583.

[29] A. Moharana, R. Varma, Subsynchronous Resonance in SingleCage Self-Exicted-Induction-Generator-Based Wind Farm to SeriesCompensated Lines, IET Generation, Transmission \& Distribution 5 (12) (2011) 1221-1232. 
[30] F. Mei, B. Pal, Modal Analysis of Grid-Connected Doubly Fed Induction Generators, IEEE Transactions on Energy Conversion 22 (3) (2007) 728736 .

[31] O. Anaya-Lara, N. Jenkins, P. Cartwright, M. Hughes, Wind Energy Generation: Modelling and Control, Wiley, 2009.

[32] L. Fan, R. Kavasseri, Z. Miao, C. Zhu, Modeling of DFIG-Based Wind Farms for SSR Analysis, IEEE Transactions on Power Delivery 25 (4) (2010) 2073-2082.

[33] L. Fernández, C. García, J. Saenz, F. Jurado, Equivalent Models of Wind Farms by Using Aggregated Wind Turbines and Equivalent Winds, Energy Conversion and Management 50 (3) (2009) 691-704.

[34] F. Milano, M. Anghel, Impact of Time Delays on Power System Stability, IEEE Transactions on Circuits and Systems I: Regular Papers 59 (4) (2012) 889-900. 